\title{
Association between the Casein Kinase I Epsilon Gene Region and Subjective Response to D-Amphetamine
}

\author{
Jeremy Veenstra-VanderWeele', Asfia Qaadir², Abraham A Palmer, Edwin H Cook Jr' and \\ Harriet de Wit*,2 \\ IInstitute of Juvenile Research, Department of Psychiatry, University of Illinois at Chicago, Chicago, IL, USA; ${ }^{2}$ Department of Psychiatry, \\ University of Chicago, Chicago, IL, USA; ${ }^{3}$ Department of Human Genetics, University of Chicago, Chicago, IL, USA
}

\begin{abstract}
Animal models suggest that the casein kinase I epsilon gene (Csnk/e) contributes to variability in stimulant response. Csnkle is a key component in the Darpp-32 (Dopamine-And-cAMP-Regulated-Phosphoprotein-32 kDa) second messenger pathway and has been implicated in previous pharmacological and pharmacogenetic studies in mice. Mice bred for methamphetamine sensitivity showed linkage to the region of chromosome 15 that contains Csnkle and also showed a I0-fold increase in expression of Csnk le. We used a doubleblind, crossover design in healthy human volunteers to test association between polymorphisms in the CSNKIE region and subjective response to placebo, 10, or $20 \mathrm{mg}$ of oral D-amphetamine. Repeated-measures ANOVA was used to analyze interactions between genotype and drug response. The primary outcome measure, subjects' ratings of whether they felt a drug effect (Drug Effects Questionnaire $(D E Q)$ ), revealed a significant effect $(p=0.010)$ at one single-nucleotide polymorphism (rs I 35745). Subjects with more copies of the rs $135745 \mathrm{C}$ allele were more sensitive to the low dose of $\mathrm{D}$-amphetamine $(p=0.00 \mathrm{I})$, which corresponded to a leftward shift in the dose-response curve. These findings demonstrate the successful translation of pharmacogenetic results from mice to humans. Neuropsychopharmacology (2006) 31, I056- 1063. doi:I 0. I038/sj.npp. I 300936; published online 12 October 2005
\end{abstract}

Keywords: translational; association; stimulant; amphetamine; substance abuse; pharmacogenetic

\section{INTRODUCTION}

Individuals display a wide range of subjective, behavioral, and cardiac responses to stimulant drugs (Nurnberger et al, 1982; de Wit et al, 1986; Chait, 1993; Hutchison et al, 1999; Gabbay, 2003). Within clinical settings, patients with narcolepsy and Attention Deficit Hyperactivity Disorder (American Psychiatric Association, 1994) show variability in their responses to the stimulants most commonly used as treatment (Mitler et al, 1993; Spencer et al, 1996). Similarly, considerable variability is seen in the mood-enhancing effects of stimulants (Brauer and de Wit, 1996), which may underlie varying vulnerability to stimulant abuse and dependence. A number of factors have been studied as potential predictors of subjective response to stimulant administration, including personality traits (Hutchison et al, 1999), cognitive states (Mitchell et al, 1996), and menstrual cycle (White et al, 2002).

*Correspondence: Dr H de Wit, Department of Psychiatry, University of Chicago, 584I S. Maryland Avenue, MC 3077, Chicago, IL 60637, USA, Tel: + I 773702 1537, Fax: + I 773702 7698,

E-mail: hdew@uchicago.edu

Received 19 May 2005; revised 29 August 2005; accepted 6 September 2005

Online publication: 12 September 2005 at http://www.acnp.org/ citations/Npp09| 205050338/default.pdf
Genetic variation in the dopamine pathway may also account for some of the variability in the response to stimulants (Cubells et al, 2000; Mattay et al, 2003; Hamarman et al, 2004; Lott et al, 2005; Stein et al, 2005). The direct action of amphetamine on the dopamine pathway is via vesicular release of dopamine and via alteration of dopamine transporter function, which results in blockade of reuptake from the synapse and reverse transport of dopamine into the synapse (Jones et al, 1998). Initial genetic association studies have been limited to the dopamine transporter itself, dopamine receptors, and enzymes involved in dopamine production and degradation. Variants in the dopamine transporter gene (DAT1), the dopamine beta-hydroxylase gene $(D B H)$, and the catechol $O$-methyltransferase gene (COMT), have been found to be associated with differences in response to stimulant drugs in humans (Cubells et al, 2000; Roman et al, 2001; Mattay et al, 2003; Lott et al, 2005; Stein et al, 2005).

We have employed a translational genetics approach to expand the field of candidate genes to include central elements of the dopamine second messenger pathways. Many animal studies have sought to understand the second messenger pathways that are affected by amphetamine and related stimulants. Greengard and others have elucidated the components of the second messenger pathway for dopaminergic signaling, which centers around Darpp-32 
(Dopamine-And-cAMP-Regulated-Phosphoprotein-32 kDa) and the genes that interact with it, including casein kinase 1, which positively regulates the activity of Darpp-32 (Greengard, 2001). Darpp-32 has been shown to be a critical regulator of the locomotor response to stimulant drugs in rodents (Greengard, 2001; Gould and Manji, 2005).

The complementary approaches of linkage and gene expression have been used to identify genes in animal models of amphetamine response (Wayne and McIntyre, 2002; Schadt et al, 2003; Monks et al, 2004). Using mouse lines that had been selectively bred for high (HMACT) or low (LMACT) response to methamphetamine (MA) (Kamens et al, 2005), Palmer et al (2005) identified a quantitative trait locus (QTL) for this trait in a region of chromosome 15 that contains casein kinase 1 epsilon gene (Csnkle). To identify candidate genes within that QTL, they examined gene expression differences in selected mouse lines. They found 10-fold higher expression of Csnkle in the nucleus accumbens of drug-naive mice from the HMACT vs the LMACT line. This higher expression was attributed to an expression QTL (eQTL) that co-maps with both the QTL for MA sensitivity and the physical location of Csnkle in the mouse genome, suggesting that the eQTL may be causally responsible for the difference in MA sensitivity. These findings are consistent with a previous study that implicated the same chromosomal region in sensitivity to cocaine-induced stimulation in mice (Jones et al, 1999).

In the present study, we examined the genetic association between acute responses to amphetamine and singlenucleotide polymorphisms (SNPs) in the CSNK1E gene region in healthy volunteers under controlled laboratory conditions. Based on results from mouse studies, we hypothesized that human genetic variation affecting expression or function of CSNK1E would modulate amphetamine response. In order to limit the number of comparisons performed, we planned in advance to focus our primary analysis on the Drug Effects Questionnare (DEQ) Feel Drug visual analog scale (VAS). We also selected in advance two secondary measures that reflect important components of the amphetamine response: the 49-item Addiction Research Center Inventory (ARCI) MBG scale, an index of euphoric drug response, and the Profile of Mood States (POMS) Anxiety scale, a measure of anxious mood. In the case of a significant result, we planned to use exploratory analyses with additional scales to understand the underlying components of subjective response reflected in the primary findings.

\section{MATERIALS AND METHODS}

\section{Subjects}

Healthy male and female volunteers $(N=101)$, aged $18-35$ years, were recruited by posters, advertisements, and wordof-mouth referrals. To reduce variability due to tolerance or withdrawal from nicotine or caffeine, volunteers were excluded if they smoked more than 10 cigarettes per week or consumed more than three cups of coffee per day. Candidates underwent a structured clinical psychiatric interview and a physical examination, and completed several screening questionnaires. They also completed a psychiatric symptom checklist (SCL-90; Derogatis, 1983), the Michigan Alcoholism Screening Test (Selzer, 1971), and a health questionnaire with a detailed section on current and lifetime drug use. All subjects obtained an electrocardiogram (EKG) and received a physical examination by a physician. Volunteers were excluded if they had any current medical condition requiring medication, any current or past medical condition considered to be a contraindication for amphetamine (eg hypertension or abnormal EKG), any current Axis I psychiatric disorder (DSM IV, 1994), if they had been treated for a substance use disorder or had a history of legal, personal or employment problems related to drug use, if they had less than a high school education, were not fluent in English, or if they worked a night shift. Women who were pregnant or lactating, or planning to become pregnant during the study were excluded.

\section{Design}

The study used a three-session crossover design, in which each subject received placebo and D-amphetamine (10 and $20 \mathrm{mg}$ ), under double-blind conditions and in randomized order. The subjective, physiological, and behavioral effects of amphetamine were recorded over $4 \mathrm{~h}$ after drug administration. Subjects were genotyped after all subjects had completed the behavioral phase of the study. Genotyping was performed blind to the behavioral data.

\section{Procedure}

Subjects first attended an orientation session to provide informed consent, practice test, and questionnaires, complete a personality questionnaire, and give a blood sample for genotyping. Subjects were instructed to abstain from taking drugs, including alcohol, nicotine, and caffeine, for $24 \mathrm{~h}$ before each session and to fast from midnight the night before the sessions. Subjects were tested individually, and remained in a comfortably furnished room with television and reading materials for the $4 \mathrm{~h}$ session. Subjective and behavioral tasks were administered via computer. Volunteers could watch emotionally neutral movies and read during the sessions when measurements were not being taken. The study was approved by the Institutional Review Board of The University of Chicago and was carried out in accordance with the Helsinki Declaration of 1975 .

The three sessions were conducted from 0900 to 1300 hours, at least $48 \mathrm{~h}$ apart. Women were tested during the follicular phase of their menstrual cycle because responses to amphetamine are dampened during the luteal phase (White et al, 2002). After drug and pregnancy testing, subjects consumed a light breakfast and completed baseline subjective, behavioral, and physiologic measures. At 0930 hours, they ingested a capsule containing D-amphetamine (10 or $20 \mathrm{mg}$ ) or placebo with $100 \mathrm{ml}$ of water. At $30,60,90$, 150 , and $180 \mathrm{~min}$ after capsule ingestion, heart rate, blood pressure, and temperature were measured, and subjects completed ratings of drug effects and mood. At 1300 hours, subjects left the laboratory. After completing the three sessions, subjects were debriefed and paid. 


\section{Dependent Measures}

Subjective drug effects were assessed using three standardized measurements: the DEQ, the POMS (McNair et al, 1971; Johanson and Uhlenhuth, 1980), and the ARCI (Martin et al, 1971). The DEQ consists of four VAS on which subjects rated whether they feel the drug, like the drug, feel high, and want more of the drug, on a $100 \mathrm{~mm}$ line (Johanson and Uhlenhuth, 1980). The POMS (McNair et al, 1971; Johanson and Uhlenhuth, 1980) is a 72-item adjective checklist with a scale sensitive to several mood states, including anxiety, depression, vigor, fatigue, friendliness, anger, elation, arousal, confusion, and positive mood. The ARCI (Martin et al, 1971) consists of true-false questions designed to measure drug-specific effects, including two stimulant scales (amphetamine (A) and benzedrine group $(B G)$ ), a euphoria (MBG) scale, a sedative (PCAG) scale, a Marijuana (M) scale, and a dysphoria (LSD) scale (Foltin and Fischman, 1991). From these questionnaires, one primary measure and two secondary measures were selected to capture the prototypic effects of amphetamine: the $\mathrm{DEQ}$ Feel Drug scale, the POMS Anxiety scale, and the ARCI MBG (Euphoria) scale.

Physiological effects, including heart rate and blood pressure, were measured before capsule administration and at repeated intervals in the $4 \mathrm{~h}$ after the capsule as described above.

\section{Genotyping}

Three SNPs flanking the CSNK1E gene region (see Figure 1) on chromosome 22, rs135745 (C_11748661), rs1005473 (C_2506145), and rs199764 (C_2988713) were genotyped using TaqMan ${ }^{\circledR}$ Genotyping Assays provided by Applied Biosystems (Foster City, CA, www.appliedbiosystems.com). These polymorphisms were chosen because available data suggested that they had high heterozygosity and were not in a high degree of linkage disequilibrium with one another, and they would thus be informative for association analysis (www.appliedbiosystems.com, SNPBrowser). PCR was carried out in a $5 \mu \mathrm{l}$ volume containing $2.5 \mu \mathrm{l}$ of $2 \times$ TaqMan $^{\circledR}$ Universal Master Mix, $0.25 \mu \mathrm{l}$ of $20 \times$ SNP Genotyping Assay Mix, and $10 \mathrm{ng}$ of DNA. PCR was run on a PerkinElmer 9700 Thermocycler (Applied Biosystems) according to the following protocol: a single $2 \mathrm{~min}$ step at $50.0^{\circ} \mathrm{C}$ $\left(\right.$ AmpErase ${ }^{\mathbb{R}}$ ), a single $10 \mathrm{~min}$ step at $95.0^{\circ} \mathrm{C}$ (enzyme activation), and 40 cycles in which the DNA was denatured at $92.0^{\circ} \mathrm{C}$ for $15 \mathrm{~s}$ and then reannealed and extended at $58.0^{\circ} \mathrm{C}$ for $1 \mathrm{~min}$. PCR products were analyzed on an LJL Analyst AD fluorescence microplate reader (LJL Biosystems, Sunnyvale, CA, www.moleculardevices.com) in the University of Chicago DNA Sequencing and Genotyping Core, and genotype clusters were identified using TaqAnalysis soft- ware, part of the PAARManager software suite developed as part of the Pharmacogenetics Research Network (PGRN).

\section{Data Analysis}

Subjects genotyped at the three SNPs in the CSNK1E gene region (see Figure 1) were categorized into three groups at each polymorphism (homozygotes for the first allele, heterozygotes, and homozygotes for the second allele). Of 101 original study participants, DNA was not available from one subject due to loss of the blood sample. Additionally, little DNA was available from another nine subjects due to limited DNA extraction yield. These nine subjects were genotyped for rs 135745 but not the other two SNPs since they showed no evidence for association with the primary outcome measure or either secondary outcome measure in the partial sample. One subject was excluded from analysis on Euphoria because responses were consistently at the top of the scale, indicating invalid reporting on this scale. No other examples of invalid reporting were detected.

Ethnicity was compared for each of the genotype groups at the three SNPs using $\chi^{2}$ tests. Subjects who indicated two ethnic identities were included with subjects identifying themselves as multiethnic. Additional demographic characteristics (see Table 2) for the three rs 135745 genotype groups were compared using ANOVA or $\chi^{2}$ tests. To determine whether the only statistically significant difference observed (lifetime opiate use, $p=0.04$ ) contributed to the observed group differences in the primary outcome measures, independent samples $t$-tests were conducted, with difference in average score over time on each drug dose $v s$ placebo as the dependent variable. Possible population stratification of the primary outcome measure by ethnicity was additionally considered by performing a repeated-measures ANOVA. Ethnicity was the grouping factor, baseline (predrug) scores were subtracted from the score at each time point to generate a difference score, and dose $(0,10$, and $20 \mathrm{mg}$ ) and time (five time points after capsule ingestion) were the two within-subjects factors, comprising a $3 \times 3 \times 5$ repeated-measures ANOVA. In addition, baseline differences across genotype groups on the primary outcome measure and both secondary outcome measures were assessed using one-way ANOVA, with placebo trial predrug score as the dependent measure. Similarly, differences in placebo response across genotype groups on the primary outcome measure and both secondary outcome measures were assessed using repeated-measures ANOVA with genotype as the grouping factor and time as the one within-subjects factor.

Hardy-Weinberg equilibrium for each marker and linkage disequilibrium between the markers were analyzed using the HaploView software (http://www.broad.mit.edu/ mpg/haploview/index.php) (Barrett et al, 2005). HaploView

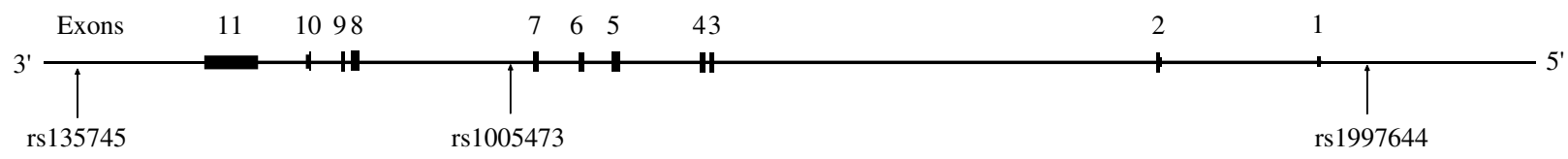

$5 \mathrm{~KB}$

Figure I Genomic structure of CSNKIE is shown to scale including I I exons spanning $27.4 \mathrm{~kb}$. The coding region is indicated by large boxes, and the untranslated region is indicated by smaller boxes. The three polymorphisms genotyped in this study are indicated with arrows. 
was also used to generate a linkage disequilibrium map of the CSNK1E region for all SNPs with available HapMap data (Supplementary Figure 4) (The International HapMap Consortium, 2003).

Analysis of subjective response to amphetamine was conducted for the rs135745 and rs1005473 SNPs in all subjects. The rs199764 SNP was analyzed only in Caucasian subjects due to a significant divergence from expected genotype frequencies for the rs199764 SNP in AfricanAmerican subjects. Subjective measures were compared for the three genotype groups at each SNP using separate repeated-measures ANOVAs (SPSS 12.0) for each of the outcome measures. Genotype was the grouping factor, baseline (predrug) scores were subtracted from the score at each time point to generate a difference score, and dose (0, 10 , and $20 \mathrm{mg}$ ) and time (five time points after capsule ingestion) were the two within-subjects factors, comprising a $3 \times 3 \times 5$ repeated-measures ANOVA. The primary outcome measure was the DEQ Feel Drug scale. Separate repeated-measures ANOVAs limited to either Caucasian, African-American, or Asian-American ethnic categories were also conducted for the primary outcome measure. Two secondary outcome measures, the ARCI MBG (Euphoria) scale, and the POMS Anxiety scale, were also analyzed for each SNP. When the primary outcome measure revealed a significant effect for the rs135745 SNP, exploratory follow-up analyses of the other DEQ, ARCI, and POMS subscales were conducted using separate repeated-measures ANOVAs, conducted as above. Post hoc analyses, to assess contribution of each dose to the drug by genotype interaction, were conducted with repeated-measures ANOVAs (SPSS 12.0) as above but limiting the dose factor to only two doses $(0 \mathrm{mg}$ and either $10 \mathrm{mg}$ or $20 \mathrm{mg}$ ), comprising two separate $3 \times 2 \times 5$ repeated-measures ANOVAs. Post hoc analyses with repeated-measures ANOVAs limited to either Caucasian, African-American, or Asian-American ethnic categories were also conducted for the primary outcome measure.

\section{RESULTS}

\section{Subjects}

Genotype frequencies for each SNP are shown in Table 1. The genotypes of the three SNPs did not deviate significantly from Hardy-Weinberg disequilibrium $(p>0.2)$. The three SNPs showed only a limited degree of linkage disequilibrium with one another (rs135745-rs1005473 $D^{\prime}=0.27, r^{2}=0.01 ;$ rs135745-rs1997644 $D^{\prime}=0.13, r^{2}=0.02$; rs1005473-rs1997644 $\left.D^{\prime}=0.19, \quad r^{2}=0.00\right)$. The HapMap

Table I Observed Genotype Counts for CSNKIE SNPS

\begin{tabular}{llccr}
\hline & & \multicolumn{3}{c}{ Genotype } \\
\cline { 3 - 5 } SNP & Position & I/I & I/2 & $\mathbf{2 / 2}$ \\
\hline rs|35745(C/G) & 37008137 & 21 & 38 & 32 \\
rsl005473(A/C) & 37018873 & 79 & 11 & 2 \\
rs1997644(A/G) & 37039722 & 17 & 45 & 28 \\
\hline
\end{tabular}

data was consistent with this observation and showed low intermarker linkage disequilibrium in the $3^{\prime}$ region of the gene (Supplementary Figure 4) (The International HapMap Consortium, 2003). For this reason, haplotype analysis is not presented here.

The three genotype groups for each SNP were similar on most demographic information. However, ethnic stratification for rs1997644 was significant for African-American subjects, who had a relative excess of the $\mathrm{G}$ allele $\left(\chi^{2}=7.51\right.$, $p=0.02)$. All further analyses of that SNP were conducted with Caucasian subjects only. No significant stratification by ethnicity was observed at the rs 135745 or rs 1005473 SNPs. Two subjects declined to answer the question about ethnicity. Table 2 shows the demographic characteristics of the three genotype groups at the rs135745 SNP. The three groups were similar with respect to age, gender, and education. The groups reported similar lifetime and current drug use, except that the $\mathrm{C} / \mathrm{C}$ homozygotes had fewer members with lifetime use of opiates $\left(\chi^{2}=6.54, p=0.04\right)$. In a separate analysis, we found no relationship between lifetime opiate use and the primary outcome measure. We also found no relationship between ethnicity and the primary outcome measure. Baseline (predrug) scores did not differ across any of the three genotypes. Response to placebo did not differ across any of the three genotypes.

Table 2 Demographic Characteristics and Substance Use for Subjects in the Three Rs 135745 Genotype Groups

\begin{tabular}{|c|c|c|c|}
\hline Demographic characteristics & $\begin{array}{c}\text { Group } \\
\text { C/C }\end{array}$ & $\begin{array}{c}\text { Group } \\
\text { C/G }\end{array}$ & $\begin{array}{c}\text { Group } \\
\text { G/G }\end{array}$ \\
\hline Ethnicity, n (2 did not answer) & 21 & 41 & 35 \\
\hline \% White (54 total) & 47.6 & 61.0 & 54.3 \\
\hline \% Black (20 total) & 33.3 & 17.1 & 17.1 \\
\hline \% Asian ( 12 total) & 4.8 & 9.8 & 20.0 \\
\hline \% Multiethnic (I I total) & 14.3 & 14.6 & 8.6 \\
\hline Overall, $n$ & 22 & 43 & 35 \\
\hline Age (mean (years)) & $24.0 \pm 4.0$ & $24.4 \pm 4.3$ & $23.2 \pm 4.0$ \\
\hline Gender (\% male) & 36.4 & 55.8 & 51.4 \\
\hline Education (mean (years)) & $14.8 \pm 1.8$ & $15.2 \pm 1.4$ & $14.9 \pm 1.8$ \\
\hline \multicolumn{4}{|l|}{ Current substance use } \\
\hline Alcohol (mean drug/week) & $3.7 \pm 3.2$ & $4.2 \pm 3.5$ & $4.4 \pm 3.1$ \\
\hline Cigarettes (mean cigarettes/week) & $0.4 \pm 1.3$ & $1.1 \pm 2.8$ & $0.8 \pm 2.0$ \\
\hline Caffeine (mean cups/day) & $1.2 \pm 1.5$ & $1.3 \pm 1.3$ & $1.4 \pm 1.3$ \\
\hline Marijuana (\% yes) & 23 & 26 & 26 \\
\hline Marijuana (mean times/month) & $1.5 \pm 3.5$ & $0.9 \pm 2.9$ & $0.7 \pm 1.9$ \\
\hline \multicolumn{4}{|l|}{ Lifetime substance use } \\
\hline Stimulants (\% ever used) & 23 & 14 & 20 \\
\hline Sedatives (\% ever used) & 4.5 & 4.7 & 8.6 \\
\hline Opiates* (\% ever used) & 0 & 11.6 & 22.9 \\
\hline Marijuana (\% ever used) & 81.8 & 76.7 & 65.7 \\
\hline Hallucinogens (\% ever used) & 31.8 & 44.1 & 31.4 \\
\hline Inhalants (\% ever used) & 18.2 & 11.6 & 8.6 \\
\hline
\end{tabular}

Comparisons across the groups were made using one-way ANOVA for continuous data and $\chi^{2}$ tests for frequency data $(* 0<0.05)$ 


\section{Overall Amphetamine Effects}

When data from all subjects were considered together, amphetamine produced its expected effects on the primary outcome measure and both secondary outcome measures, with increased DEQ Feel Drug and ARCI Euphoria $(p<0.001$, drug main effect from repeated-measures ANOVA), and increased POMS Anxiety $(p=0.004$, drug main effect from repeated-measures ANOVA). For most measures, drug effects appeared by $60 \mathrm{~min}$ and peaked between 90 and $120 \mathrm{~min}$ after capsule ingestion. The effects were dose-dependent for most measures.

\section{rs135745 Genotype Differences in Drug Effects}

Primary outcome measure. The three genotype groups at the rs135745 SNP had different patterns of response to D-amphetamine on the primary outcome measure, the DEQ Feel Drug scale (Genotype $\times$ Drug interaction on $3 \times 3 \times 5$ repeated-measures ANOVA, $p=0.010)$. This significant effect was confined to the $10 \mathrm{mg}$ dose condition (Figure 2). Post hoc comparison revealed that the genotype groups differed significantly only in their response to the $10 \mathrm{mg}$ dose of amphetamine in comparison to placebo (Genotype $\times$ Drug interaction on $3 \times 2 \times 5$ repeated-measures ANOVA for $10 \mathrm{mg}$ dose, $p=0.001$ ), with higher scores for subjects with the $\mathrm{C} / \mathrm{C}$ genotype. No interaction was detected at $20 \mathrm{mg}$ $(p=0.391)$. No significant Genotype $\times$ Drug $\times$ Time interaction was observed for the primary outcome measure.

The response pattern for each of the ethnic categories analyzed separately was similar to the overall response pattern (Supplementary Figure 5). The statistical significance for each measure differed across ethnicities (Supplementary Table 4). For Caucasian subjects, there was a trend for a difference in response to the $10 \mathrm{mg}$ dose in comparison to placebo. For African-American subjects, there was a significant difference in response to the $10 \mathrm{mg}$ dose in comparison to placebo. For Asian-American subjects, there was a significant difference observed in the overall $3 \times 3 \times 5$ repeated-measures ANOVA as well as in the post hoc analysis at the $10 \mathrm{mg}$ dose compared to placebo.

Secondary outcome measures. A similar pattern to the primary outcome measure was observed on one of the two secondary outcome measures, the ARCI MBG (Euphoria) scale (Genotype $\times$ Drug interaction, $p=0.018$ ). This significant effect was also confined to the $10 \mathrm{mg}$ dose condition (Figure 2). For ARCI MBG (Euphoria), post hoc comparisons revealed the same pattern of a significant Genotype $\times$ Drug interaction at $10 \mathrm{mg}(p=0.009)$ but not at $20 \mathrm{mg}(p=0.185)$. No significant rs135745 Genotype $\times$ Drug interaction was observed for POMS Anxiety $(p=0.428)$. No significant Genotype $\times$ Drug $\times$ Time interaction was observed for either of the secondary measures.

Additional exploratory analyses for other ARCI, DEQ, and POMS subscales are shown in Supplementary Table 3 and Supplementary Figure 3.

\section{rs1005473 Genotype Differences in Drug Effects}

There were no significant Genotype $\times$ Drug interactions on either the primary or secondary outcome measures for the three genotype groups at the rs1005473 SNP.
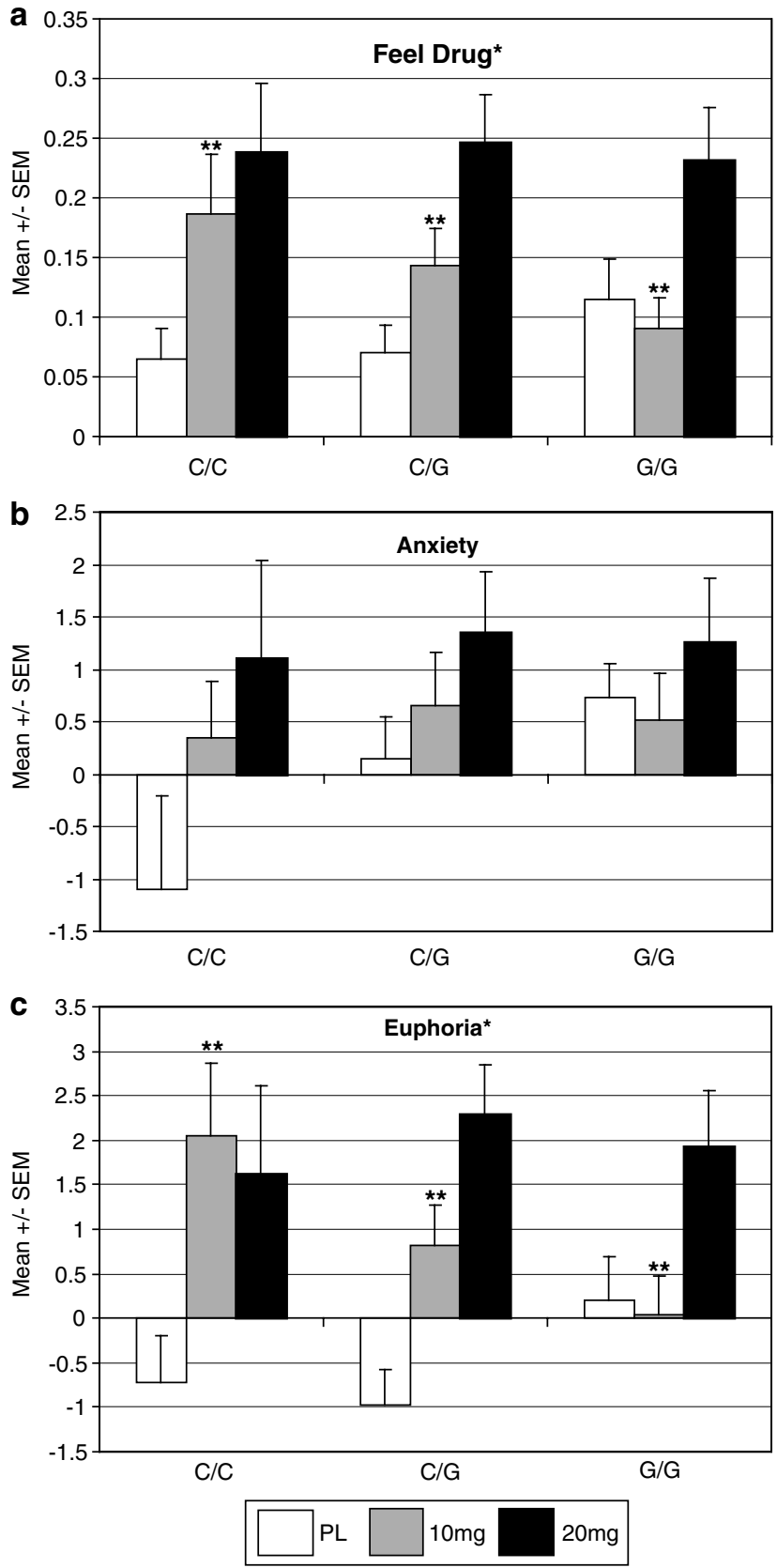

Figure 2 Mean \pm SEM change from predrug time point averaged over time in the three rs/35745 genotype groups. The primary outcome measure, DEQ Feel Drug, and the two secondary outcome measures, POMS Anxiety and ARCI MBG Euphoria, are shown. The number of subjects in each genotype group was $C / C(n=22), C / G(n=43)$, and $G / G$ $(n=35)$. The graphs are color-coded, with white $(\mathrm{PL})$ representing placebo, gray $(10 \mathrm{mg})$ representing the $10 \mathrm{mg}$ dose of D-amphetamine, and black $(20 \mathrm{mg}$ ) representing the $20 \mathrm{mg}$ dose. *Outcome measures with a globally significant repeated-measures ANOVA. **Drug dose with a significant post hoc repeated-measures ANOVA.

\section{rs1997644 Genotype Differences in Drug Effects}

In an analysis confined to Caucasian subjects, there were no significant Genotype $\times$ Drug interactions on either the primary or secondary outcome measures for the three genotype groups at the rs1997644 SNP. 


\section{DISCUSSION}

The primary finding of this paper is that a polymorphism in rs 135745 , a noncoding SNP $3 \mathrm{~kb} 3^{\prime}$ of the $3^{\prime}$-UTR of CSNK1E, is associated with subjective response to amphetamine on the primary outcome measure, DEQ Feel Drug. An association in the same direction was also seen for ARCI MBG (Euphoria), one of the secondary measures. Genotypes at the two other SNPs showed no association with the primary or secondary measures. The Genotype $\times$ Drug interactions observed were amphetamine dose-dependent, with interactions observed for rs135745 genotypes with DEQ Feel Drug and ARCI MBG (Euphoria) response in the $10 \mathrm{mg}$ but not $20 \mathrm{mg}$ condition. That is, at $10 \mathrm{mg}$, subjects with the rs135745 C/C genotype reported feeling greater drug effects and more components of a drug-induced euphoria scale in comparison to subjects with the other genotypes. The pattern of genotype by drug interaction was consistent with an additive effect at this SNP, such that increased dose of the rs $135745 \mathrm{C}$ allele corresponded to increased response to the $10 \mathrm{mg}$ dose. The pattern of this association is a leftward shift in the dose-response curve for subjects with this genotype (Figure 2).

CSNK1E was hypothesized to be associated with sensitivity to acute amphetamine administration based on previous findings in mice (Palmer et al, 2005). Palmer et al (2005) selectively bred mice for four generations for either high or low sensitivity to the acute locomotor stimulant effects of MA (Kamens et al, 2005). Analysis of gene expression in drug-naive mice from the final selection generation identified higher expression of both Csnkle and Darpp-32 in the HMACT line. The region that contains Csnkle was also found to contain a QTL for MA sensitivity, and complementary data from WebQTL (Chesler et al, 2005) showed that this same region of mouse chromosome 15 influenced Csnkle transcript abundance, indicating the presence of a cis-acting eQTL. Palmer et al (2005) concluded that Csnkle was a high probability candidate for influencing acute response to MA in mice. Parallel work by Jones et al (1999) found that the region of mouse chromosome 15 that contains Csnkle also contains a QTL for sensitivity to the locomotor-stimulant effects of cocaine at a $5 \mathrm{mg} / \mathrm{kg}$ dose and for binding of several dopaminergic ligands in samples of brain tissue. Interestingly, Jones et al (1999) did not find linkage to chromosome 15 when higher doses of cocaine were administered, suggesting that variation in Csnkle may be most important in determining response to lower doses, a finding supported by the present data.

CSNK1E is a compelling candidate gene because of its role as a second messenger in a number of important signaling pathways. Most relevant to this study is its role in regulating the phosphorylation state of Darpp-32, which is known to be a critical component of the locomotor response to dopaminergic drugs (Greengard, 2001; Gould and Manji, 2005). Csnk1e positively regulates the activity of Darpp-32 by phosphorylating the Ser-137 site (Desdouits et al, 1995; Greengard, 2001) and thereby preserves the activated state of Darpp-32, which leads to multiple downstream effects (Greengard, 2001; Gould and Manji, 2005). Csnk1e also has important roles in two other signaling pathways that may be relevant to stimulant response. First, it acts as a regulator of the circadian clock genes by phosphorylation of mPer 1 (period) (Price et al, 1998; Takano et al, 2004a). Deletion of the homologue of CSNK1E in Drosophila (doubletime) (Kloss et al, 1998) has been shown to block cocaine sensitization (Andretic et al, 1999). Furthermore, a recent study of individuals with delayed sleep phase syndrome and non- $24 \mathrm{~h}$ sleep-wake cycle syndrome identified a missense mutation that increases the activity of the protein product of CSNK1E and appears protective against these disorders (Takano et al, 2004b). Finally, Csnkle regulates the Wnt/ Frizzled signaling pathway (Habas and Dawid, 2005) and has been shown to positively modulate the activation of Gsk3, a downstream target of Darpp-32 (Svenningsson et al, 2003) that is important for the response to stimulant drugs (Beaulieu et al, 2004).

A few other candidate genes have also been studied for their role in regulating response to stimulant drugs. Most prominently, genotypes at a polymorphism in the $3^{\prime}$-UTR of the DAT1 gene have been associated with response to stimulants, both in the acute laboratory setting and in the clinical treatment of ADHD. Lott et al (2005) described association of the DAT1 9/9 genotype with diminished ability to feel a drug effect of amphetamine (DEQ) using the same paradigm and study sample employed here. Stein et al (2005) also noted diminished response of subjects with the DAT1 9/9 genotype to the treatment effects of methylphenidate. Two other genes, the brain-derived neurotrophic factor gene $(B D N F)$ and the serotonin transporter gene (SLC6A4), were also studied using the same paradigm and sample described here, but no association was detected with subjects' ability to feel a drug effect (DEQ) (H de Wit, unpublished observation); although nominally significant associations with secondary and exploratory measures were detected. Research on the relationship between prefrontal cortical function and a functional val158met polymorphism in the COMT has recently been extended to include amphetamine response. Subjects with the low-activity met allele were found to exhibit a diminished effect of amphetamine on working memory (Mattay et al, 2003). Finally, polymorphisms in the $D B H$ that are associated with plasma enzyme activity have been found to be associated with cocaine-induced paranoia in a clinical sample (Cubells et al, 2000). The COMT and DBH polymorphisms have not yet been examined for their role in determining acute response to stimulants in a laboratory setting. Thus far, candidate gene association studies have been the primary approach to identifying genes involved in response to stimulants, but the genome-wide linkage approach may also hold much promise. The only published linkage study of stimulant abuse or dependence reported suggestive evidence for linkage of cocaine dependence to chromosome 10 , as well as significant evidence of linkage for related traits to chromosomes 9 and 12 (Gelernter et al, 2005). As further studies confirm and clarify association of multiple genes within the amphetamine response pathway, it will be possible to explore interactions between functional polymorphisms in multiple genes; however, larger samples will be required to provide sufficient statistical power to examine such epistatic interactions.

While the preliminary findings presented here are exciting and represent translation of findings from animal research into the human arena, a number of caveats deserve mention. First, the associated polymorphism is a noncoding 
SNP $3 \mathrm{~kb} 3^{\prime}$ of the last exon of CSNK1E, and is unlikely to itself account for a change in function that could explain change in response to amphetamine. Additionally, no previous studies in humans have considered possible interindividual variation in CSNK1E expression or function. The other two SNPs that were studied were not in a high degree of linkage disequilibrium with $\operatorname{rs} 135745\left(r^{2}<0.02\right.$, $\left.D^{\prime}<0.30\right)$. Gene resequencing followed by denser genotyping of polymorphisms with construction of haplotypes surrounding rs135745 would be necessary to identify a potentially functional variant or variants in CSNK1E.

Another significant problem is the absence of methodology to control for population stratification in case-control studies of quantitative traits. Such methods exist for dichotomous traits (Pritchard et al, 2000), but studies of quantitative traits, including pharmacogenetic studies, have typically used genotype comparison groups without genomic control. We found no evidence of stratification at rs135745 using self-reported ethnicity. We also found no effect of ethnicity on the primary outcome variable, suggesting that differences between the self-reported ethnic categories do not account for the significant association. Furthermore, we observed a similar pattern of response in each ethnicity (Supplementary Figure 5). With diminished power to detect association, we found a trend toward association in Caucasian subjects, a significant post hoc association in African-American subjects, and a significant primary analysis in Asian-American subjects. Future studies should be powered to detect association in one ethnicity alone.

Finally, CSNK1E is the fourth gene that we have studied in this population that was ascertained using a cluster of measures of subjective response. We carefully identified a primary outcome measure and two secondary outcome measures and used conservative, broad-based initial statistics, but we report $p$-values that are not corrected for multiple testing. The initial finding for the DEQ Feel Drug measure $(p=0.010)$ would sustain correction for multiple genes tested, but it is difficult to construct appropriate statistical correction schemes for multiple polymorphisms in some degree of linkage disequilibrium. Replication of these findings will be crucial to understanding the role of CSNK1E in stimulant response.

If the association reported here between CSNK1E and amphetamine response is confirmed, there are interesting implications both for future research on response to stimulants and also for general research design in translational genetic studies. The finding described here offers an example of an intermediate step between animal models and human clinical populations. Our use of a carefully controlled pharmacogenetic experimental design parallels the animal model that we sought to extend to the human population and may account for our ability to detect association. Many translational genetic studies skip directly to a clinical phenotype, such as stimulant abuse or treatment of ADHD (Cubells et al, 2000; Stein et al, 2005). Having observed association in normal humans within a laboratory setting, we will now study CSNK1E in clinical populations, but our laboratory findings will lead us to focus specifically on sensitivity to stimulants. The clinical implications could extend to other disorders as well, such as bipolar disorder, where amphetamine-induced behavioral and cellular changes have been used as a surrogate phenotype for mania (Niculescu et al, 2000; Ogden et al, 2004). Finally, if replicated, this finding supports the further use of convergent evidence from signal transduction pathways, gene expression, and linkage studies in rodent models to identify genes that may have important variation across species.

\section{ACKNOWLEDGEMENTS}

This work was supported by NIH (DA02812; RR00055) and by the Jean Young and Walden W Shaw Foundation. We thank Jen McDonald and Michelle Dassenger for technical assistance.

\section{REFERENCES}

American Psychiatric Association (1994). Diagnostic and Statistical Manual of Mental Disorders, 4th edn. American Psychiatric Association Press Inc.: Washington, DC.

Andretic R, Chaney S, Hirsh J (1999). Requirement of circadian genes for cocaine sensitization in Drosophila. Science 285: 1066-1068.

Barrett JC, Fry B, Maller J, Daly MJ (2005). HaploView: analysis and visualization of $\mathrm{LD}$ and haplotype maps. Bioinformatics 21: 263-265.

Beaulieu JM, Sotnikova TD, Yao WD, Kockeritz L, Woodgett JR, Gainetdinov RR et al (2004). Lithium antagonizes dopaminedependent behaviors mediated by an AKT/glycogen synthase kinase 3 signaling cascade. Proc Natl Acad Sci USA 101: 5099-5104.

Brauer LH, de Wit H (1996). Subjective responses to Damphetamine alone and after pimozide pretreatment in normal, healthy volunteers. Biol Psychiatry 39: 26-32.

Chait LD (1993). Factors influencing the reinforcing and subjective effects of D-amphetamine in humans. Behav Pharmacol 4: 191-199.

Chesler EJ, Lu L, Shou S, Qu Y, Gu J, Wang J et al (2005). Complex trait analysis of gene expression uncovers polygenic and pleiotropic networks that modulate nervous system function. Nat Genet 37: 233-242.

Cubells JF, Kranzler HR, McCance-Katz E, Anderson GM, Malison $\mathrm{RT}$, Price LH et al (2000). A haplotype at the DBH locus, associated with low plasma dopamine beta-hydroxylase activity, also associates with cocaine-induced paranoia. Mol Psychiatry 5: 56-63.

de Wit H, Uhlenhuth EH, Johanson CE (1986). Individual differences in the reinforcing and subjective effects of amphetamine and diazepam. Drug Alcohol Depend 16: 341-360.

Derogatis L (1983). SCLR-90-R. Administration, Scoring and Procedures Manual-II for the Revised Version and Other Instruments of the Psychopathology Rating Series. Clinical Psychometric Research: Towson, MD.

Desdouits F, Siciliano JC, Greengard P, Girault JA (1995). Dopamine- and cAMP-regulated phosphoprotein DARPP-32: phosphorylation of Ser-137 by casein kinase I inhibits dephosphorylation of Thr-34 by calcineurin. Proc Natl Acad Sci USA 92: 2682-2685.

Foltin RW, Fischman MW (1991). Assessment of abuse liability of stimulant drugs in humans: a methodological survey. Drug Alcohol Depend 28: 3-48.

Gabbay FH (2003). Variations in affect following amphetamine and placebo: markers of stimulant drug preference. Exp Clin Psychopharmacol 11: 91-101.

Gelernter J, Panhuysen C, Weiss R, Brady K, Hesselbrock V, Rounsaville B et al (2005). Genomewide linkage scan for cocaine 
dependence and related traits: significant linkages for a cocainerelated trait and cocaine-induced paranoia. Am J Med Genet B 136: $45-52$.

Gould TD, Manji HK (2005). DARPP-32: a molecular switch at the nexus of reward pathway plasticity. Proc Natl Acad Sci USA 102: 253-254.

Greengard P (2001). The neurobiology of slow synaptic transmission. Science 294: 1024-1030.

Habas R, Dawid IB (2005). Dishevelled and Wnt signaling: is the nucleus the final frontier? J Biol 4: 2 .

Hamarman S, Fossella J, Ulger C, Brimacombe M, Dermody J (2004). Dopamine receptor 4 (DRD4) 7-repeat allele predicts methylphenidate dose response in children with attention deficit hyperactivity disorder: a pharmacogenetic study. J Child Adolesc Psychopharmacol 14: 564-574.

Hutchison KE, Wood MD, Swift R (1999). Personality factors moderate subjective and psychophysiological responses to D-amphetamine in humans. Exp Clin Psychopharmacol 7: 493-501.

Johanson CE, Uhlenhuth EH (1980). Drug preference and mood in humans: D-amphetamine. Psychopharmacology (Berlin) 71: 275-279.

Jones BC, Tarantino LM, Rodriguez LA, Reed CL, McClearn GE, Plomin R et al (1999). Quantitative-trait loci analysis of cocainerelated behaviours and neurochemistry. Pharmacogenetics 9: 607-617.

Jones SR, Gainetdinov RR, Wightman RM, Caron MG (1998). Mechanisms of amphetamine action revealed in mice lacking the dopamine transporter. J Neurosci 18: 1979-1986.

Kamens HM, Burkhart-Kasch S, McKinnon CS, Li N, Reed C, Phillips TJ (2005). Sensitivity to psychostimulants in mice bred for high and low stimulation to methamphetamine. Genes Brain Behav 4: 110-125.

Kloss B, Price JL, Saez L, Blau J, Rothenfluh A, Wesley CS et al (1998). The Drosophila clock gene double-time encodes a protein closely related to human casein kinase Iepsilon. Cell 94: 97-107.

Lott DC, Kim SJ, Cook Jr EH, de Wit H (2005). Dopamine transporter gene associated with diminished subjective response to amphetamine. Neuropsychopharmacology 30: 602-609.

Martin WR, Sloan JW, Sapira JD, Jasinski DR (1971). Physiologic, subjective, and behavioral effects of amphetamine, methamphetamine, ephedrine, phenmetrazine, and methylphenidate in man. Clin Pharmacol Ther 12: 245-258.

Mattay VS, Goldberg TE, Fera F, Hariri AR, Tessitore A, Egan MF et al (2003). Catechol $O$-methyltransferase val158-met genotype and individual variation in the brain response to amphetamine. Proc Natl Acad Sci USA 100: 6186-6191.

McNair D, Lorr M, Droppleman L (1971). Profile of Mood States (Manual). Educational and Industrial Testing Service: San Diego.

Mitchell SH, Laurent CL, de Wit H (1996). Interaction of expectancy and the pharmacological effects of D-amphetamine: subjective effects and self-administration. Psychopharmacology (Berlin) 125: 371-378.

Mitler MM, Hajdukovic R, Erman MK (1993). Treatment of narcolepsy with methamphetamine. Sleep 16: 306-317.

Monks SA, Leonardson A, Zhu H, Cundiff P, Pietrusiak P, Edwards $S$ et al (2004). Genetic inheritance of gene expression in human cell lines. Am J Hum Genet 75: 1094-1105.

Niculescu III AB, Segal DS, Kuczenski R, Barrett T, Hauger RL, Kelsoe JR (2000). Identifying a series of candidate genes for mania and psychosis: a convergent functional genomics approach. Physiol Genom 4: 83-91.

Nurnberger Jr JI, Gershon ES, Simmons S, Ebert M, Kessler LR, Dibble ED et al (1982). Behavioral, biochemical and neuroendocrine responses to amphetamine in normal twins and 'well-state' bipolar patients. Psychoneuroendocrinology 7: 163-176.

Ogden CA, Rich ME, Schork NJ, Paulus MP, Geyer MA, Lohr JB et al (2004). Candidate genes, pathways and mechanisms for bipolar (manic-depressive) and related disorders: an expanded convergent functional genomics approach. Mol Psychiatry 9: 1007-1029.

Palmer AA, Verbitsky M, Suresh R, Kamens HM, Reed CL, Li N et al (2005). Gene expression differences in mice divergently selected for methamphetamine sensitivity. Mammalian Genome 16: 291-305.

Price JL, Blau J, Rothenfluh A, Abodeely M, Kloss B, Young MW (1998). double-time is a novel Drosophila clock gene that regulates PERIOD protein accumulation. Cell 94: 83-95.

Pritchard J, Stephens M, Rosenberg N, Donnelly P (2000). Association mapping in structured populations. Am J Hum Genet 67: 170-181.

Roman T, Schmitz M, Polanczyk G, Eizirik M, Rohde L, Hutz M (2001). Attention-deficit hyperactivity disorder: a study of association with both the dopamine transporter gene and the dopamine D4 receptor gene. Am J Med Genet (Neuropsychiatric Genet) 105: 471-478.

Schadt EE, Monks SA, Drake TA, Lusis AJ, Che N, Colinayo V et al (2003). Genetics of gene expression surveyed in maize, mouse and man. Nature 422: 297-302.

Selzer ML (1971). The Michigan alcoholism screening test: the quest for a new diagnostic instrument. Am J Psychiatry 127: $1653-1658$.

Spencer T, Biederman J, Wilens T, Harding M, O'Donnell D, Griffin S (1996). Pharmacotherapy of attention-deficit hyperactivity disorder across the life cycle. J Am Acad Child Adolesc Psychiatry 35: 409-432.

Stein MA, Waldman ID, Sarampote CS, Seymour KE, Robb AS, Conlon C et al (2005). Dopamine transporter genotype and methylphenidate dose Response in children with ADHD. Neuropsychopharmacology 30: 1374-1382.

Svenningsson P, Tzavara ET, Carruthers R, Rachleff I, Wattler S, Nehls $M$ et al (2003). Diverse psychotomimetics act through a common signaling pathway. Science 302: 1412-1415.

Takano A, Isojima Y, Nagai K (2004a). Identification of mPer1 phosphorylation sites responsible for the nuclear entry. $J$ Biol Chem 279: 32578-32585.

Takano A, Uchiyama M, Kajimura N, Mishima K, Inoue Y, Kamei $\mathrm{Y}$ et al (2004b). A missense variation in human casein kinase I epsilon gene that induces functional alteration and shows an inverse association with circadian rhythm sleep disorders. Neuropsychopharmacology 29: 1901-1909.

The International HapMap Consortium (2003). The international HapMap project. Nature 426: 789-796.

Wayne ML, McIntyre LM (2002). Combining mapping and arraying: an approach to candidate gene identification. Proc Natl Acad Sci USA 99: 14903-14906.

White TL, Justice AJ, de Wit H (2002). Differential subjective effects of D-amphetamine by gender, hormone levels and menstrual cycle phase. Pharmacol Biochem Behav 73: 729-741.

Supplementary Information accompanies the paper on Neuropsychopharmacology website (http://www.nature.com/npp). 